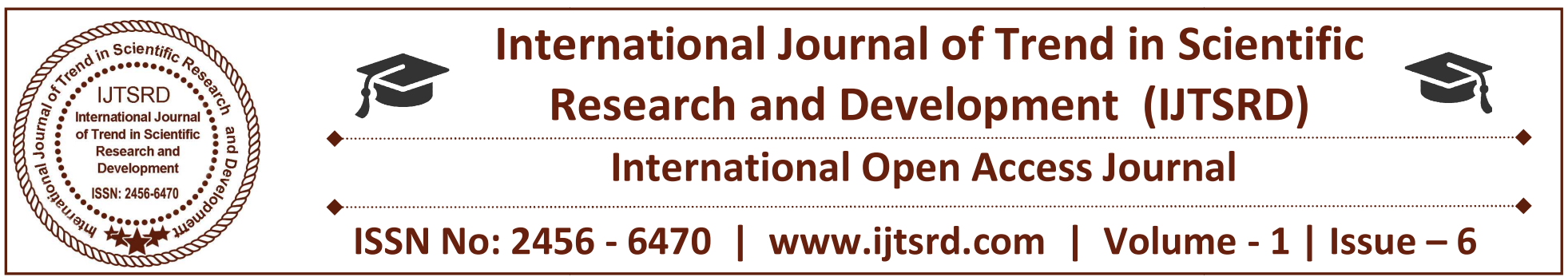

\title{
Technological Progress from Ancient Stone Age to Recent Polymer Chemistry World
}

\author{
Rita Awasthi \\ Department of Chemistry, \\ Brahmanand P.G.College, Kanpur
}

\author{
Deepti Shikha \\ Department of Chemistry, \\ Brahmanand P.G.College, Kanpur
}

\section{ABSTRACT}

Technological artifacts are products of a society's economy, a force for economic growth, and a large part of everyday life. Technological innovations affect, and are affected by, a society's cultural traditions. The invention of tools and techniques is evidence of a society's ability to solve problems that were encountered in everyday life. Many sociologists and anthropologists have created social theories dealing with social and cultural evolution. Some declare technological progress to be the primary factor driving the development of human civilization. In other words, societies advance when their technologies advance. There were three main time periods or ages when tools were the main technological development: The Stone Age, The Bronze Age and the Iron Age. It was the growth of the ancient civilizations which produced the greatest advances in technology and engineering, advances which stimulated other societies to adopt new ways of living and governance. From ancient civilizations until now, there have been many inventions, discoveries, and development of technologies. Many different cultures have had significant impacts upon technological advances. Polymers are said to be the most versatile materials on earth. Almost all of the products we use in our daily lives contain polymers.

\section{INTRODUCTION \\ AND HISTORICAL DEVELOPMENT}

Our ancient civilization goes back to more than 5000 years; starting with the Indus Valley Civilisation around $2500 \mathrm{~B}$.C.The history of technology is the history of the invention of tools and techniques [1]. These inventions have enabled people to create and accomplish many new things. The Stone Age is a broad prehistoric period during which stone was widely used to make implements with a sharp edge, a point, or a percussion surface. The period lasted roughly 3.4 million years, and ended between 6000 BCand 2000 BC with the advent of metal working. The Bronze Age was a period of time between the Stone Age and the Iron Age when bronze was used widely to make tools, weapons, and other implements. The most significant characteristic of the Bronze Age was the surge in metallurgy. The early part of the Bronze Age was referred to as the Chalcolithic Age. Copper and bone were the materials used to make the tools and implements that humans began using. Copper metal works were first known to the people of the Mesopotamian regions and gradually spread to other civilizations. Bronze, an alloy of copper and tin, was soon discovered and manufactured in large quantities because of its durability, About $1500 \mathrm{BC}$ another step was taken in the Mediterranean, perhaps first in Asia Minor which was to derive an even harder metal, called iron from its ore durability. By $1200 \mathrm{BC}$, the discovery of iron ended the Bronze Age and then commenced the Iron Age [2].

Humans have progressed from the Stone Age through the bronze, iron and steel ages into its current age, the age of polymers, an age in which synthetic polymers will be the material of choice [3]. 
Stone Age $\rightarrow$ Bronze Age $\rightarrow$ Iron Age $\rightarrow$ Polymer Age

The first synthetic plastic was discovered in 1907 when a Belgian born chemist, Dr. Leo H. Baekeland, reacted phenol and formaldehyde under pressure using hexamethylenetetramine as a catalyst for the reaction. The result was a thermosetting "phenolic" plastic he named Bakelite. Compared to other plastics available at the time, such as celluloid, Baekeland's thermosetting phenolic was more stable. Once molded, this new material would not burn or soften when reheated, or dissolve. This benefit made it stand out from the other plastics on the market. Bakelite was an instant commercial success. It was electrically resistant, chemically stable, heat resistant, rigid, moisture and weather resistant. It was very widely used for its electrical insulating capability.

Polymeric materials have a vast potential for exciting new applications in the foreseeable future polymer uses are being developed in such diverse area as conduction and storage of electricity, heat and light, molecular based information storage and processing, molecular composites, unique separation membranes, revolutionary new forms of food processing and packaging, health, housing and transportation. Polymers are also used for most composite, electric devices, biomedical devices, optical devices and carriers in many drug delivery systems. Indeed, polymers will play an increasingly important role in all aspects of our life.

\section{EARLY CIVILIZATION AND TOOLS}

A tool is a device or a piece of equipment that typically provides a mechanical advantage in accomplishing a task or enables the accomplishment of a task not otherwise possible. The most basic tools are simple machines. When particularly intended for domestic use, a tool is often called a utensil.Stone tools were made from a variety of stones. For example, flints were shaped (or for use as cutting tools and weapons, while basalt and sand-stone were used for ground stone tools, such as quern-stones. Wood, bone, shell, antler (deer) and other materials were widely used, as well. During the most recent part of the period, sediments (such as clay) were used to make pottery.
$>$ Cutting tools, such as the knife, scissors or an axe, are wedge-shaped implements that produce a shearing force along a narrow face.

Moving tools, move large and small things. All these tools move items by some kind of force.

Concentrating force tools (like the hammer moves a nail, or the maul moves a wedge.) These operate by applying physical compression to a surface. In the case of the screwdriver, the force is sideways and called torque.

$>$ Writing implements deliver a fluid to a surface via compression to activate the ink cartridge.

$>$ Grabbing and twisting nuts and bolts with pliers, a glove, or a wrench

$>$ Inclined planes, wedges and pulleys help move large items.

$>$ Guiding and measuring tools include the ruler, set square, and straightedge.

Shaping tools, help us by making consistent and reliable shapes that fit together well and are sturdy.

$>$ Fastening tools, such as welders, rivet guns, nail guns, glue guns, and glue help us by fastening things together.

\section{STONE AGE: The first tool-makers}

This period of time is called the Stone Age because these very early men created tools from stone. The Stone Age ran from about 2 million years ago to about 10,000 years ago. Humans did not have strong claws to help them fight. They could not out run sabertoothed tigers or cave lions. Man had to get smart to survive. At this time, man began creating stone tools (Fig.1) to help live more comfortably, and to better protect themselves against the many carnivore (meat eating) animals of the time. Although this group made stone tools and weapons, these weapons were still pretty basic. The unorganized settlements of humans that were characteristic of the Stone Age developed into highly evolved civilizations. 


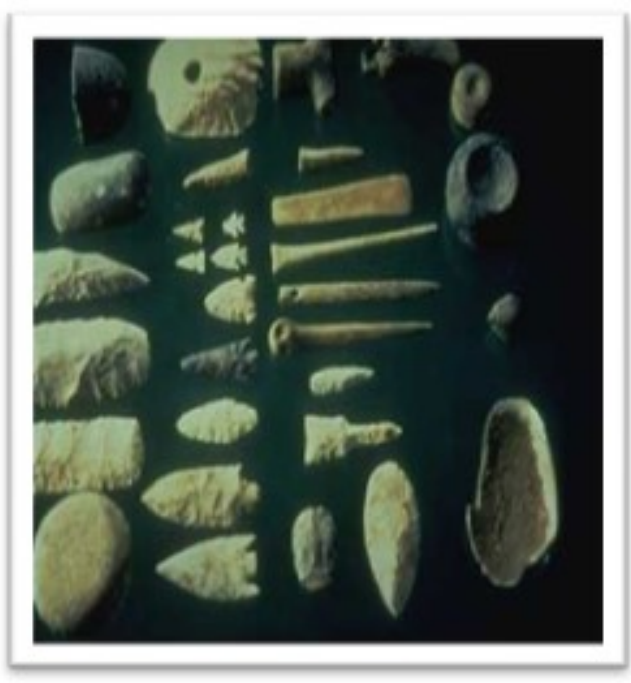

Fig.1: A collection of Stone Age tools

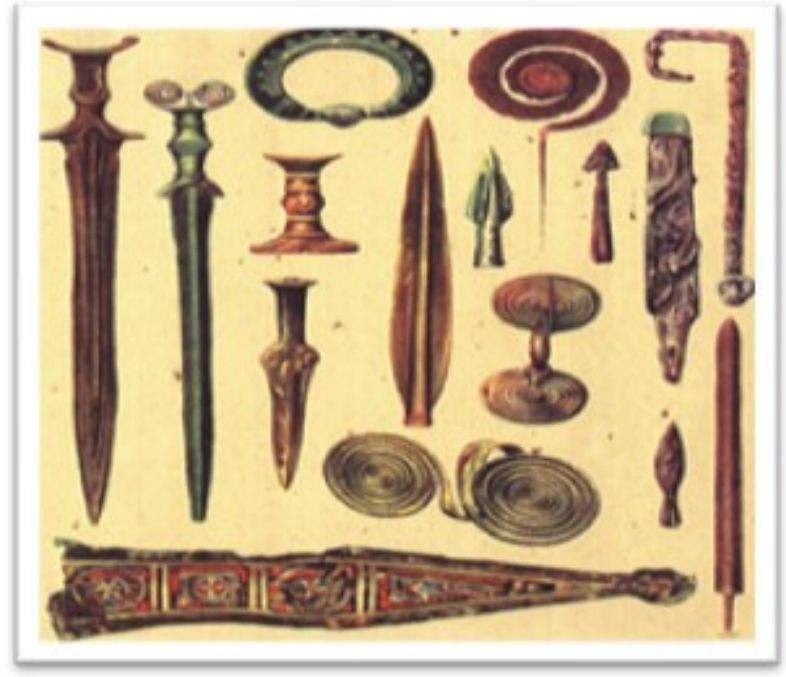

\section{THE BRONZE AGE}

The Stone Age developed into the Bronze Age after radical changes in agricultural technology which included:

$>$ development of agriculture (people began to grow crops),

$>$ animal domestication (people began to raise animals),

$>$ and the adoption of permanent settlements (people began to stay in one area).

The Bronze Age civilizations in other parts of the world were just as glorious, and were a period of learning. The Indus Valley Civilization of India became known for their civic constructions and their exemplary art and culture. The Vedas were written in the Bronze Age and form the basis of cultural life in India even today. During this period in the

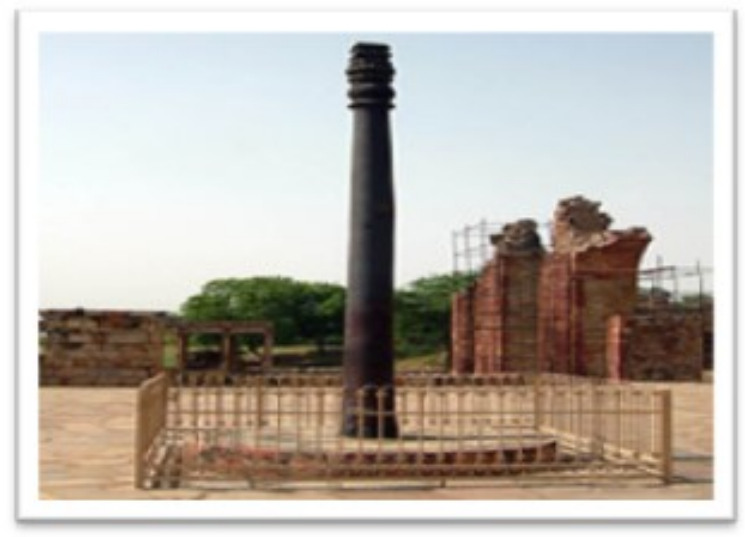

Fig.3: Pillar at Delhi

Fig.2: A collection of Bronze Age weaponry and ornaments

development of technology is when metals were first used regularly in the manufacture of tools and weapons (Fig.2).

\section{THE IRON AGE}

The Iron Age involved the adoption of iron smelting technology. It generally replaced bronze, and made it possible to produce tools which were stronger and cheaper to make than bronze equivalents. In many Eurasian cultures, the Iron Age was the last major step before the development of written language. Also developed during the Iron Age was a coin system. The iron pillar of Delhi is a 7 meter high pillar which is notable for the composition of the metals used in its construction (Fig. 3). The pillar is 98\% pure wrought iron, and is a testament that high level of skill achieved by ancient Indian ironsmiths at that time. It has catches the attention of both archaeologists and metallurgists all over the world as it has withstood corrosion for over 1,600 years in the open environment (Fig.4).

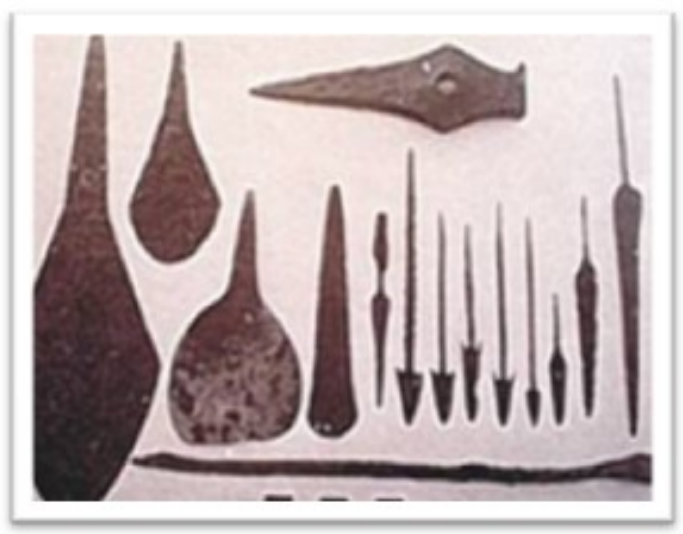

Fig.4: $\quad$ Iron Age Tools 


\section{THE POLYMER AGE}

The first modern example of polymer science is Henri Braconnot's work in the 1830 s. Braconnot, along with Christian Schonbein and others, developed derivatives of the natural polymer cellulose, producing new, semi-synthetic materials, such as celluloid and cellulose acetate. The term "polymer" was coined in 1833 by Jons Jakob Berzelius, though Berzelius did little that would be considered polymer science in the modern sense. In the 1840 s, Friedr ich Nathaniel Hayward independently discovered that adding sulphur to raw natural rubber helped prevent the material from becoming sticky. In 1844 Charles Goodyear received a U.S. patent for vulcanizing natural rubber with sulphur and heat. In 1884 Hilaire de Chardonnet started the first artificial fibre plant based on regenerated cellulose, or viscose rayon, as a substitute for silk, but it was very flammable. In 1907 Leo Baekeland invented the first synthetic polymer, a thermosetting phenolformaldehyde resin called Bakelite.

Hermann Staudinger was the first to propose that polymers consisted of long chains of atoms held together by covalent bonds. It took over a decade for Staudinger's work to gain wide acceptance in the scientific community, work for which he was awarded the Nobel Prize in 1953.

The World War II era marked the emergence of a strong commercial polymer industry. The limited or restricted supply of natural materials such as silk and rubber necessitated the increased production of synthetic substitutes, such as nylon and synthetic rubber. In the intervening years, the development of advanced polymers such as Kevlar and Teflon have continued to fuel a strong and growing polymer industry [4].

\section{POLYMERS IN TODAY'S WORLD}

Some of the most advanced polymer products being manufactured today are used in the medical industry. The angioplasty catheter is a good example of a lifesaving medical device that would not be possible without plastics. Balloon angioplasty is a minimally invasive non-surgical alternative to coronary artery bypass grafting surgery. The angioplasty balloon is used to compress obstructing plaque in a clogged artery against the arterial wall so that blood can flow freely again (Fig.5). The doctor positions the balloon of the angioplasty catheter at the site of the blockage and gently expands it to compress the plaque and create a wider opening in the artery. This procedure has a very high success rate.

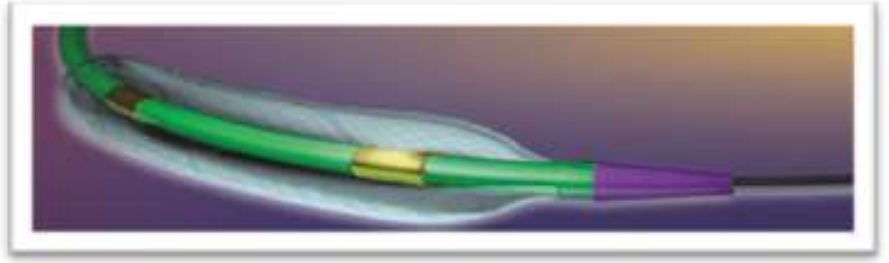

Fig.5: Angioplasty balloons made from a variety of plastics

Plastics have been used for telephone housings (Fig.6) since the turn of the last century. The early black plastic phones were compression molded from thermosetting phenolic and had wall thickness up to $13 \mathrm{~mm}$. Injection molded acrylonitrile butadiene styrene (ABS) phones were introduced in the 1950's. ABS has a very high gloss, good impact resistance, and unlike phenolic, could be molded in a variety of different colors. The ABS phones had wall thicknesses of about $3 \mathrm{~mm}$. Today's cell phones are injection molded using a polycarbonate \& ABS blend. The compact and lightweight phones of today have wall thicknesses in the range of $1 \mathrm{~mm}$. Telephones are a good example of how plastic products evolve over time.
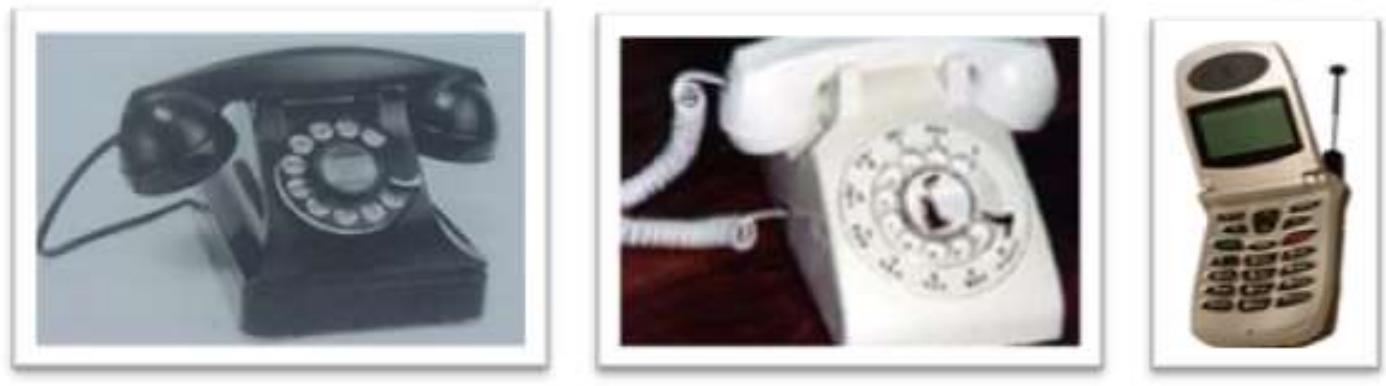

Fig.6: Early black plastic phones to compact and lightweight phones of today 
Polyurethane could be the most versatile plastics available today. A polyurethane is formed by reacting a polyol (an alcohol with more than two reactive hydroxyl groups per molecule) with a di isocyanate or a polymeric isocyanate in the presence of suitable catalysts and additives (Fig.7).Polyurethanes can be molded, extruded, or cast, and are available as foams,

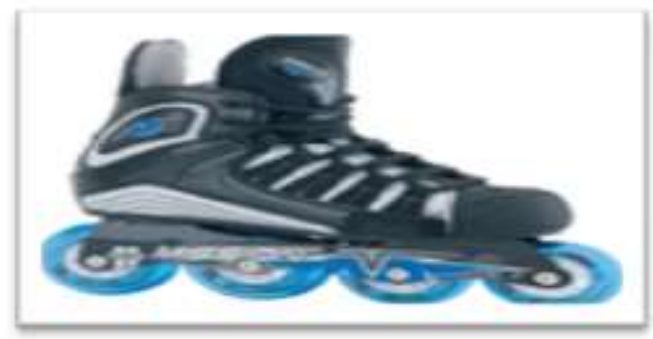

Fig.7: Polyurethrane skate wheels

In the 1960's, Stephanie Kwolek discovered an entirely new branch of synthetics known as liquid crystalline polymers. She discovered an aramid polymer that most researchers would have rejected, since it was fluid and cloudy, rather than viscous and clear. Kwolek, acting on instinct, insisted on spinning out the solution, and the result was astonishing: synthetic fibers much stiffer and stronger than any created before.The polymer fiber, named Kevlar, was first marketed in 1971.The fiber was five times stronger than steel (on a strength per weight basis) but about half the density of glass fiber. Kevlar is best known to the public as the material from which bulletproof vests are made; and in this use alone has saved thousands of lives. In fact, Kevlar has dozens of coatings, specialty adhesives and sealants. The first artificial replacement heart, the Jarvic-7, (Fig.8) was produced from a flexible and fatigue resistant polyurethane. The toughness and abrasion resistance of polyurethane make it an ideal material for applications such as in-line skate wheels.

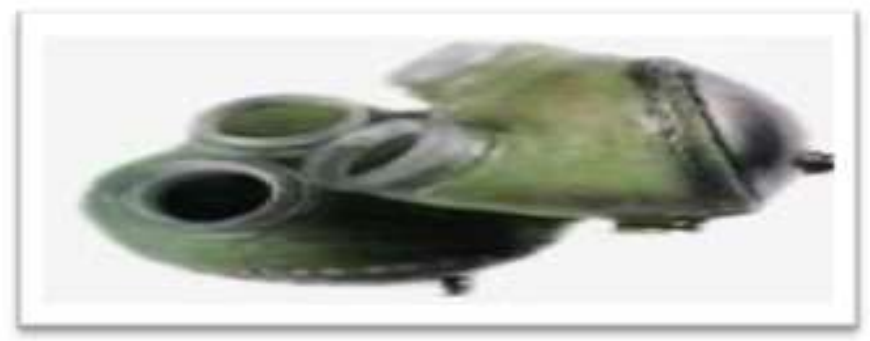

Fig.8: First artificial replacement heart: JARVIC-7

important applications, including radial tire cord, brake pads, racing boat sails, aircraft components, and suspension bridge cables.

On July 20, 1969, the human race accomplished its greatest technological achievement of all time when Neil Armstrong set foot on the moon. This feat would not have been possible without many materials science developments. Plastics played an important role. For example, the Apollo A7L space suits were a multi-layer plastic structure comprised of nylon fabric, neoprene coated nylon fabric, Dacron fabric, and Tefloncoated fabric etc (Fig.9). The "fish bowl" helmet was produced from transparent polycarbonate. The space suits of today make even more extensive use of plastics.
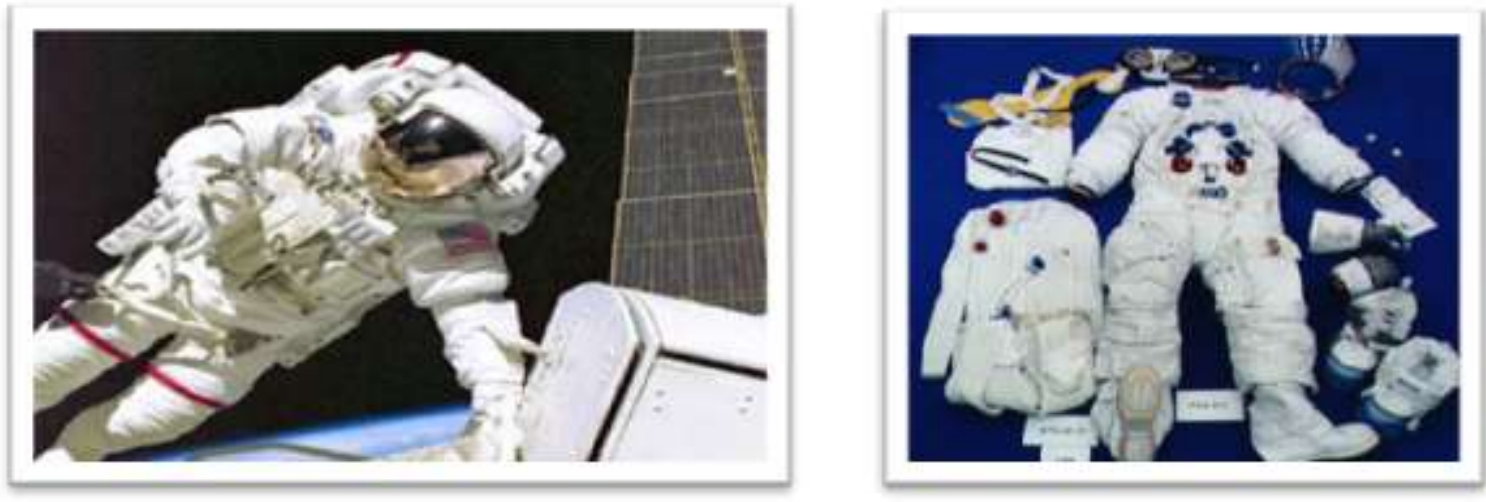

Fig.9: Role of polymers in space science 


\section{DISCUSSION}

About $3500 \mathrm{BC}$, it was discovered that copper may be made harder by melting it together with tin, which formed bronze [5,6]. This was the intellectual step, and therefore when a people made the jump to bronze, they had made a significant cultural leap. The technological leap was the higher heat source needed for iron, where the advantage was that iron ore was abundant and widespread and therefore cheap. Although the scarcity of education in polymer science is slowly diminishing but it is still evident in many areas. The polymers industry started in the late 1800's with polymers produced from natural resources. These included polymers based on shellac, cellulose and natural rubber. As the petrochemical industry developed in the 1900 's, a wider variety of synthetic polymers were introduced and production of polymers based on natural resources declined even as the overall consumption of plastics rose. These synthetic polymers had more consistent quality and properties, and could be produced at a lower cost.

\section{CONCLUSION}

As the world develops, the demand for our nonrenewable and limited resources has grown rapidly. This has led to feedstock shortages and petrochemical price increases. People come from ancient, rich and elaborate cultures that created a wealth of technologies in many areas. Hopefully, over time, there will be more studies in this area and more people will know of these great achievements. Ironically, manufactures of polymers are now turning back to natural and renewable resources for manufacturing polymers. Many of the agricultural based products are also available. The food packaging, medical, automotive, electronics, building construction, and textile industries all make extensive use of plastics and elastomers. Plastics are used extensively in the medical industry. One of the most interesting medical applications for polymers is the "artificial hip". Each prosthesis is made up of two parts: the acetabular component (socket portion) that replaces the acetabulum, and the femoral component (stem portion) that replaces the femoral head. The femoral component is made of titanium, while the acetabular component is made of a metal shell with a plastic inner socket liner. The plastic liner is molded from Ultra High Molecular Weight Polyethylene and acts like a bearing which is extremely tough, abrasion resistant and has a very low coefficient of friction.
This is a very good example of how plastics and metals work together to enhance our quality of life.

The developments in new materials and process technologies that have occurred over the past 150 years have been very significant. Exciting new developments and discoveries related to polymers are happening all of the time.

\section{REFERENCES:}

1) http://earlyhumans.mrdonn.org/index.html

2) Asua, José M. Polymer Reaction Engineering (Hardcover - 392 pages). Wiley, John \& Sons. ISBN 978-1-4051-4442-1(August 2007).

3) Brydson, J. A., Plastics Materials, Butterworth Heinemann, 2000.

4) Kohan, M., Nylon Plastics, Wiley- Interscience, New York, 1973.

5) Chakrabarti, D. K. 1992, The Early Use of Iron in India, Oxford University Press, New Delhi.

6) Agrawal, D. P. and Ghosh, A. (eds.). 1971, The Copper- bronze Age in India. Munshiram Manohar Lal, New Delhi. 